\title{
REVIEW
}

\section{The cardiac complications of COVID-19: many publications, multiple uncertainties}

\author{
Abdallah Al-Mohammad1,2, David G Partridge2,3, Graham Fent², Oliver Watson², Nigel T Lewis², Robert F Storey1,2, \\ Michael Makris ${ }^{1,2}$ and Timothy J Chico (D)1,2
}

'Department of Infection, Immunity and Cardiovascular Diseases, University of Sheffield, Sheffield, UK

2Sheffield Teaching Hospitals NHS Foundation Trust, Sheffield, UK

3Florey Institute for Host Pathogen Research, University of Sheffield, Sheffield, UK

Correspondence should be addressed to T J Chico: t.j.chico@sheffield.ac.uk

\begin{abstract}
Since the first description of COVID-19 in December 2019, more than 63,000 publications have described its virology, clinical course, management, treatment and prevention. Most physicians are now encountering, or will soon encounter, patients with COVID-19 and must attempt to simultaneously assimilate this avalanche of information while managing an entirely novel disease with few guiding precedents. It is increasingly clear that, although primarily a respiratory illness, COVID-19 is associated with cardiovascular complications. However, the true incidence of direct cardiac complications remains unclear, as all complications thus far reported can also occur in patients without COVID-19. In this review, we briefly summarise and critically appraise the data on cardiac complications associated with COVID-19 and describe some cases from our own experience. We identify unresolved questions and highlight the many uncertainties in this developing field.
\end{abstract} Key Words

- COVID-19

- myocardial injury

- infection

- inflammation

- microvasculature

- vascular disease

- thrombosis

\section{Introduction}

Coronavirus disease 2019 (COVID-19) caused by the severe acute respiratory syndrome coronavirus 2 (SARS-CoV2), was first reported in Wuhan in China in the autumn of 2019. It rapidly disseminated to cause a pandemic declared by the World Health Organization in March 2020, which the world continues to struggle against.

By May 2020, multiple case reports (1, 2, 3, 4, 5, 6, $7,8,9,10,11,12,13)$ and descriptions on social media suggested COVID-19 is associated with a range of cardiac complications. At the time of first submission of this review, a PubMed search of 'COVID' and 'Cardiovascular' yielded 653 studies; this had increased to 3055 by the time of final submission. A number of excellent reviews already describe the potential cardiac complications of COVID$19(14,15,16,17,18)$. However, new data are emerging constantly, justifying our attempt to put this literature into context alongside our own clinical experience.

It is still challenging to define the true incidence of cardiac complications, and particularly to determine what proportion relates specifically to COVID-19, rather than more generally to critical illness or even coincidence. Any disease with a substantial mortality that may require invasive ventilatory and circulatory support is associated with cardiac complications such as cardiomyopathy, myocardial infarction, arrhythmia, hypotension and heart failure, particularly in patients with pre-existing conditions placing them at higher risk. The distinction between direct and indirect causation of cardiac complications is important in considering what treatment or management may improve outcomes. 
We and colleagues serve a 1000-bed hospital with tertiary services for both infectious diseases and cardiology which had treated over 1450 COVID-19 cases by May 2020. Thus far we have encountered fewer cardiac complications than we initially anticipated, although our case studies reported here show these do occur. In this review, we, therefore, examine what cardiac complications may occur, how frequent these are, and highlight the many uncertainties about the cardiac risks of COVID-19.

\section{Coronaviruses and heart disease}

Coronaviruses were described in 1965 as a cause of the common cold $(19,20)$ and cause a substantial proportion of respiratory tract infections globally. Until the present millennium, coronaviruses were believed to cause mild self-limiting disease (21). However, the recognition that viruses, including coronaviridae, can affect the heart is not new. A link between viral infections and inflammation of the pericardium (pericarditis) (22), myocardium (myocarditis) $(23,24)$ and impaired ventricular function and heart failure due to cardiomyopathy (25) has long been recognised. Although coronaviridae were occasionally linked to these diseases before 2003, coxsackie, adenovirus, enteroviruses, human immunodeficiency virus (HIV), and influenza have been far more frequently associated with cardiac complications. Since viral testing (especially histologically on cardiac biopsy or at autopsy) is rarely performed clinically, even in severe cases, and never in mild community-based disease, the true incidence of viral or post-viral cardiac complications following coronavirus or other viral infections is poorly understood. It is, therefore, possible that non-COVID coronaviruses are associated with a greater proportion of cardiac disease than previously appreciated.

\section{Cardiac complications of SARS and MERS}

In 2003, coronavirus SARS-CoV1 was responsible for 'the first new infectious disease of the 21st Century' (26); Severe Acute Respiratory Syndrome (SARS). SARS was associated with over 8000 cases worldwide and 774 deaths, representing a case fatality rate of $9-15 \%(27,28)$. Both SARS-CoV1 and SARS-CoV2 use cell-surface angiotensin converting enzyme 2 (ACE2) to enter the host cell (29, 30). It might be expected, therefore, that COVID-19 and SARS may share a similar pattern of cardiac complications.

Despite its high mortality, SARS does not appear to have been associated with a notably high rate of direct cardiac complications. There are few reports of fulminant or severe cardiac complications with SARS, although postmortem evidence shows multisystem involvement, including small venous thrombosis (31). In 121 patients with SARS, a high rate of hypotension and tachycardia was reported (32). One patient had paroxysmal atrial fibrillation and one patient developed mild left ventricular dysfunction in the context of severe pneumonia requiring inotropic support. Persistent tachycardia has been reported (33). Although case series of cardiac arrest exist (34), this does not in itself confirm direct cardiac effects in a disease with a high fatality. In 46 SARS patients (14 mechanically ventilated) studied by serial echocardiography, one patient (a 39-year-old woman) had a severe left ventricular systolic impairment and died, although with no postmortem evidence of either infarction or myocarditis. The remaining patients showed a slight reduction in diastolic LV function compared to the assessment after recovery, but this does not confirm direct myocardial suppression.

It is unclear whether the rate of cardiac complications in SARS is comparable to that seen in COVID-19, as case numbers of SARS were far lower and sensitive cardiac markers to detect myocardial damage such as troponin were not widely available in 2003 . The rapid recognition of cardiac manifestations seen with COVID-19 suggests SARS-CoV2 may have a greater propensity to cause these than SARS-CoV1 though this is far from definite and may relate more to wider accessibility of serum cardiac-specific troponin assays (a highly sensitive marker of myocardial necrosis) and cardiac imaging, including point-of-care echocardiography. What is clear is that pre-existing cardiac conditions such as diabetes and hypertension, as well as older age significantly increase the risk of mortality or adverse outcome in SARS $(35,36,37,38)$. This pattern of susceptibility appears to be shared with both MERS (see subsequently) and COVID-19.

The coronavirus MERS-CoV was responsible for the Middle East Respiratory Syndrome (MERS) that arose in Saudi Arabia in 2012. MERS is still present, so far causing 858 deaths from 2494 confirmed cases (case fatality rate $34 \%$ ). Several sources state MERS may cause myocarditis, although we find only one case report (39) and no systematic estimate of myocarditis incidence. This complication is therefore probably low, although, like SARS, a lack of widespread troponin testing may have masked its prevalence. A characterisation of 47 MERS cases described no cardiac complications despite $60 \%$ mortality (40). There is a single case report of MERS presenting with pericarditis (41), although the distinction between the

This work is licensed under a Creative Commons Attribution-NonCommercial 4.0 International License. 

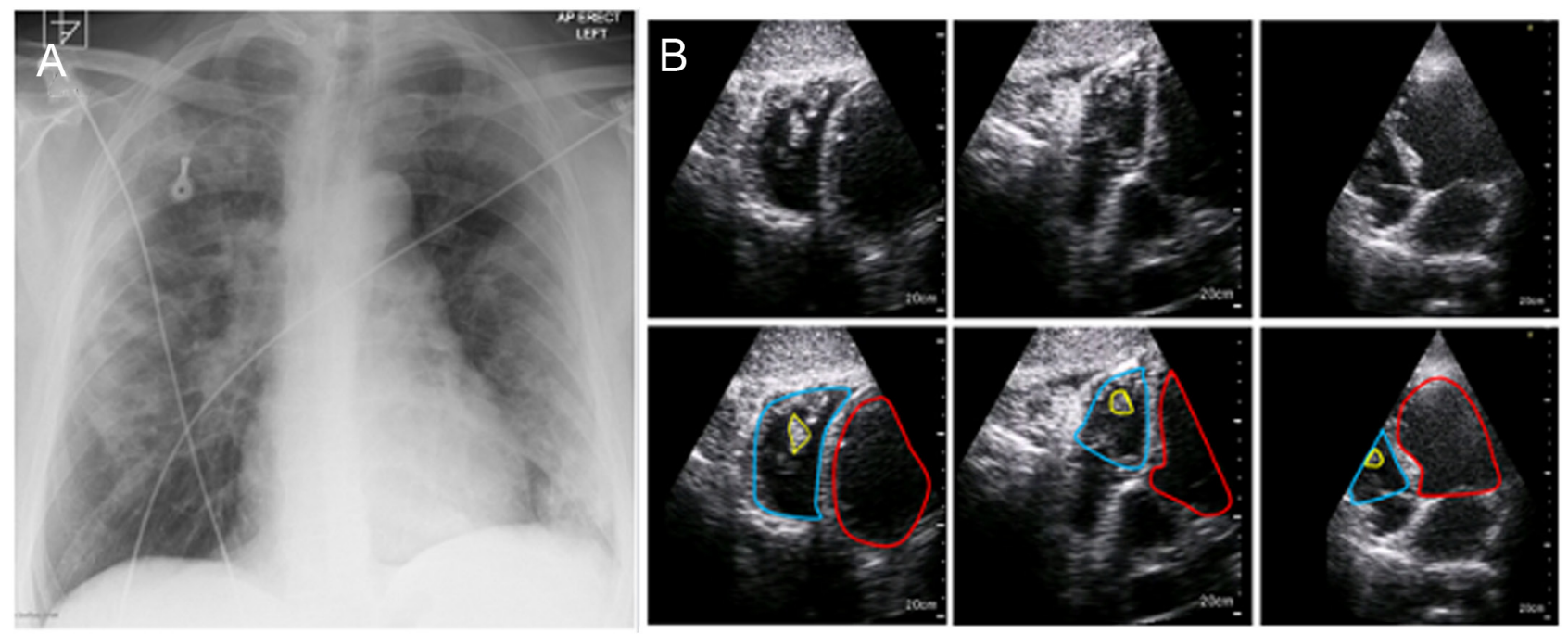

\section{Figure 1}

COVID-19 presenting with chest pain and right ventricular thrombosis. (A) Chest X-ray showing typical patchy opacities throughout both lungs and normal cardiac silhouette. (B) Series of echocardiographic images demonstrating RV thrombus. On the annotated images on the bottom row, the thrombus is highlighted in yellow, the right ventricle in blue and the left ventricle in red.

pain of pericarditis and chest infection is challenging and it is not uncommon to encounter diagnostic uncertainty. A second case of 'pericarditis' associated with MERS has been cited (14) but the MERS infection was actually acquired in ITU after surgical pericardiectomy (41).

Overall, like SARS, MERS does not appear to be associated with high rates of direct cardiac complications, although the low number of cases and high fatality rate in both diseases makes it impossible to conclude this definitively. MERS-CoV uses the dipeptidyl peptidase 4 receptor to gain entry to the host cell, raising the possibility that this different mode of pathogenesis may underlie a lower risk of direct cardiac complications compared to COVID-19. Despite little evidence of direct cardiac complications with MERS, as with SARS the rate of cardiac co-morbidity in severe MERS was high with either diabetes and/or hypertension which were present in almost 50\% in a metanalysis of 637 patients (42).

\section{Cardiac complications in COVID-19 case studies}

\section{Case 1 Myocardial injury and thrombosis}

A 61-year-old male patient with hypertension and epilepsy was referred to our primary percutaneous coronary intervention (PCI) service as a possible ST-elevation myocardial infarction after a 4-day history of malaise and diarrhoea followed by sudden onset pleuritic chest pain. ECG showed right bundle branch block with anterior and lateral ST-segment elevation. Chest X-ray (CXR) showed bilateral patchy consolidation (Fig. 1A) and SARS-CoV2 RNA PCR was positive on a nose-throat swab. Arterial blood gas showed type 1 respiratory failure and echocardiogram showed severe left ventricular (LV) systolic impairment (LV ejection fraction 30\%) with severe septal, anterior and apical hypokinesis and a large $19 \times 14 \mathrm{~mm}$ thrombus adherent to the moderator band within the right ventricular apex (Fig. 1B). He was managed with intravenous unfractionated heparin infusion, supplementary oxygen and intravenous antibiotics. CT pulmonary angiography (CTPA) and left heart catheterisation were planned but he deteriorated suddenly and died before this was performed.

\section{Case 2 Pulmonary embolism}

A 34-year-old with a past medical history of obesity and type 2 diabetes mellitus was admitted with increasing shortness of breath and 11-day history of dry cough and associated pleuritic chest pain. SARS-CoV2 RNA PCR was positive on a nose-throat swab. ECG was normal. CTPA (Fig. 2) showed bilateral acute pulmonary embolism and patchy bilateral airspace consolidation. The patient was anticoagulated with rivaroxaban and treated with oxygen. The patient recovered and was discharged.

\section{Case 3 Minor cardiac damage in mild COVID-19}

A 48-year-old hypertensive male patient of AfroCaribbean ethnicity was admitted with cough and pyrexia

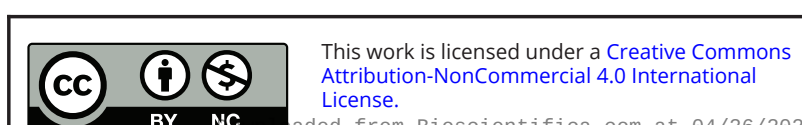
License. ded from Bioscientifica.com at 04/26/2023 12:45:36PM 


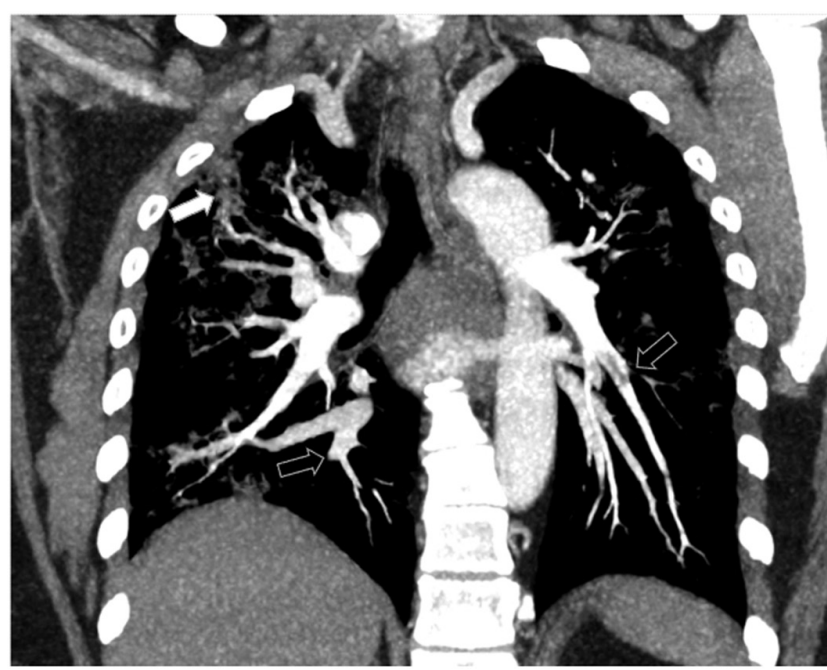

\section{Figure 2}

COVID-19 presenting with pulmonary emboli. CT pulmonary angiography showing bilateral acute pulmonary emboli (unfilled arrows) and bilateral patchy airspace consolidation (filled arrow).

but a normal CXR. SARS-CoV2 RNA PCR was positive on a nose-throat swab. He was treated with antibiotics but developed some pleuritic chest pain. His cardiac troponin level was mildly elevated, but echocardiography was normal. He recovered well and was discharged.

\section{Relationship between cardiovascular risk factors and severity of COVID-19}

As with MERS and SARS, the severity of COVID-19 is increased in patients with higher cardiovascular risk. Factors such as male sex, older age, systemic hypertension, diabetes, obesity and established cardiovascular disease appear to make the patient particularly vulnerable to both morbidity and mortality (43).

A UK study reported an overall mortality rate of 33\% in 16,479 patients with COVID-19 (16\% of all confirmed UK cases at that time). The mortality of patients on mechanical ventilation was over 50\% even though ventilated patients were younger than the average (61 years vs 72 years). In this study, age, obesity, male sex and comorbidities, including chronic cardiac disease, were independently associated with higher mortality (44).

\section{Myocardial injury and COVID-19}

Myocardial injury is commonly reported in COVID-19, identified as an elevation in serum troponin. In early case series from Wuhan, $12 \%$ of patients had raised serum troponin levels suggesting acute myocardial injury (45). In another series, 7\% of 138 admitted COVID-19 patients had elevated troponin levels, including $22 \%$ in ICU patients but only $2 \%$ of non-ICU-treated patients (46). Elevated serum troponin is associated with a much higher risk of death; in two other series, the rate of cardiac injury in admitted patients was 20-28\%, which was associated with 51-59\% mortality compared with 4-9\% mortality in those with normal troponin $(47,48)$. In addition, the rate of mechanical ventilation was substantially higher in those with cardiac injury (48). The association between myocardial injury and ventilation (primarily used for inadequate oxygenation rather than cardiac failure) suggest that overt myocardial injury in the absence of severe respiratory COVID-19 complications is relatively uncommon. However, as case 3 shows, it is possible for even very mild COVID-19 to be associated with detectible cardiac injury.

The mechanisms for myocardial injury in COVID-19 remain incompletely understood. A number of possible mechanisms are proposed but myocardial injury is likely to be multifactorial in a heterogeneous population that includes those with pre-existing coronary artery or myocardial disease. Myocardial injury can result from thrombosis. Other putative mechanisms include both direct effects of the virus on the myocytes, potentially mediated by the ACE2 receptor, or indirect effect of the infection due to the systemic inflammatory response (49). Myocarditis is defined as an inflammatory condition of the myocardium and is most commonly caused by viral infection in Europe and North America but may also be immune-mediated (50). It has been suggested that the myocardial injury seen in COVID-19 may be due to a direct viral myocarditis $(11,51)$, however definitive evidence for myocardial viral infection is not yet available. Myocarditis can be challenging to diagnose and is often reliant on clinical features and histological analysis of an endomyocardial biopsy (EMB). In the small number of published cases with significant myocardial dysfunction (clinical myocarditis) associated with COVID-19 who had $\mathrm{EMB}$, there were no characteristic histological features. A single case from Italy has shown viral inclusion bodies within EMB samples but without myocyte necrosis and only low-grade inflammation (50). Overall, although the cardiac injury in COVID-19 is likely to relate to many factors, it seems likely that direct myocarditis does occur in at least a proportion of those cases with elevated cardiac markers and profound cardiac dysfunction in the absence of pre-existing cardiac disease, although the prevalence of such cases remains unknown.

This work is licensed under a Creative Commons Attribution-NonCommercial 4.0 International License. 
When evaluating the causes and incidence of cardiac injury in COVID-19, it is important to recognise that cardiac injury in any critically ill patient is very common. In community-acquired pneumonia, $85 \%$ of ventilated patients have cardiac injury (52) and elevated troponin is also associated with a substantially higher mortality in this context (53). This makes it likely that a substantial proportion of the cardiac injury seen in COVID-19 is not related to SARS-CoV2-specific mechanisms and more related to critical illness.

An epidemic in which myocardial injury is a major component raises concern that, after recovery from the acute illness, some patients may develop left ventricular impairment and heart failure as a postinfective cardiomyopathy. So far, there are no longer-term follow-up studies of cardiac function, but the timecourse of persistent troponin elevation and any cardiac dysfunction will be important to define.

\section{Thrombosis in association with COVID-19}

The relationships between inflammation and thrombosis are well recognised (54) and so it is expected that patients with dysregulated inflammatory response in COVID-19 will have an associated prothrombotic state. However, COVID-19 is associated with a prothrombotic disorder that appears more severe even than other critical illnesses. D-dimers are generated during fibrin breakdown, the essential constituent of thrombi, and early reports from China show raised D-dimer levels in COVID-19 patients (55). In patients with severe COVID-19, survivors had lower D-dimer levels whilst a progressive elevation of D-dimer was associated with poor prognosis (56). The use of heparin thromboprophylaxis was associated with a survival advantage in patients with markedly raised D-dimer (57). Initially, it was suggested this elevated D-dimer reflected disseminated intravascular coagulation (DIC), but this is not the case as the fibrinogen and platelet count remain normal until very late in the disease (58). Indeed, we have demonstrated that D-dimer is elevated in the acute inflammatory response to sterile endotoxaemia without evidence of the classic DIC of fulminant infection (59).

In keeping with the laboratory findings in COVID-19, clinical data has confirmed a very high thrombotic risk. An early report suggested that the incidence of pulmonary emboli amongst patients with COVID-19 in ITU was 20\% despite most receiving antithrombotic treatment (60). An initial description of a cohort of 184 COVID-19 ITU patients suggested the rate of thrombotic complications was $31 \%$ (61) which was later updated to an even higher rate $(49 \%)$ of venous thromboembolism (VTE), $87 \%$ of which were pulmonary emboli (PE) (62).

The prothrombotic state in COVID-19 may partly relate to endothelial cell damage. Endothelial cells express ACE2 on their surface. Damage to endothelial cells by infection (termed endotheliitis (63)) results in transformation of the microvascular environment from anti- to pro-thrombotic. Although the exact mechanism remains unclear, there is a major increase in procoagulant factors such as factor VIII and von Willebrand factor. Concurrently, the levels of plasminogen activator inhibitor 1 (PAI1) are also increased, resulting in inhibition of fibrinolysis (64). These changes in the alveolar microenvironment result in microthrombi leading to impaired perfusion and poor oxygen exchange. The micro-thrombotic process has been termed pulmonary intravascular coagulation (PIC) to distinguish it from the more widespread process of DIC (65). Microvascular thrombosis and endothelial damage in COVID-19 may however also link this complication to myocardial injury due to ischaemia as well as an increased risk of stroke $(66,67)$. Indeed, the high frequency of thrombotic complications in COVID-19 may provide a more likely explanation of myocardial injury than both direct viral invasion of the myocardium or the impact of inflammatory response to COVID-19 on the myocardium, as discussed previously.

The number of PEs reported in ICU COVID-19 patients is much higher than with lower limb DVT. It is usually considered that PE results from clot originating in a lower limb DVT that embolises to the lungs. The observation there are widespread pulmonary microthrombi and PE with a paucity of DVT in COVID-19 led to the suggestion that what is observed is pulmonary thrombosis generated in situ in the pulmonary arteries rather than PE (68, 69). This may be of clinical importance as therapeutic anticoagulation is efficient in treating DVT and PE, but may be less effective in treating pulmonary thrombosis.

Due to the prothrombotic nature of COVID-19 infection, all patients admitted to hospital should receive thromboprophylaxis with low-molecular-weight heparin (LMWH), unless there is a contraindication such as severe thrombocytopenia. The high thrombotic rates in ITU patients, despite LMWH thromboprophylaxis, has led many to increase the thromboprophylactic dose to twice daily. Some have gone further and use full-dose anticoagulation in all patients admitted to ICU with COVID-19. A recent observational study of 2773 patients suggested that anticoagulation was associated with lower mortality in the 395 patients who were ventilated, 
although this must be interpreted with caution due to several potential confounders (70). Many randomised trials of different doses of LMWH are ongoing so hopefully the evidence will be generated soon.

When comparing COVID-19 patients with other critically ill patients, COVID-19 does seem to present a higher thrombotic risk. A comparison of 150 COVID-19 ICU patients with a group of matched non-COVID-19 ICU patients with Acute Respiratory Distress Syndrome (ARDS) observed a 2.6-fold higher risk of VTE and 6.2fold higher risk of PE in the COVID-19 group (71). Most of the thrombotic events were venous but a $2.6 \%$ arterial thrombosis rate also occurred. Arterial thrombosis in COVID-19 has been reported even in the absence of underlying atherosclerosis or other predisposing conditions (72), a possible pointer to the role of thrombosis as a potential mechanism for myocardial injury.

\section{Cardiac arrhythmia and COVID-19}

The incidence of arrhythmia in cases of COVID-19 has been reported to be $5-17 \%(47,73,74)$ with higher rates (44\%) in patients requiring intensive care (46). By far, sinus tachycardia is the most common, consistent with most systemic illnesses. Other forms of arrhythmia range from relatively benign supraventricular and atrial arrhythmias to ventricular arrhythmia and cardiac arrest. It is unsurprising that those with severe COVID-19 are more prone to arrhythmia due to indirect effects including hypoxia, septic shock, multi-organ failure and metabolic and electrolyte abnormalities (75). In keeping with this, the majority of cardiac arrests complicating COVID-19 result in non-shockable rhythms (PEA or asystole) and are likely to be respiratory (or pulmonary embolic) in origin (76). Furthermore, those patients with established or undiagnosed cardiovascular disease are more prone to arrhythmia in response to any illness due to induced ischaemia and/or myocardial injury. In patients with less severe illness or those who recover from COVID-19, the risk of arrhythmia is unknown.

There have been reports of COVID-19 patients experiencing QT prolongation (QTc > $500 \mathrm{~ms}$ ) leading to episodes of polymorphic ventricular tachycardia (Torsades de Pointes). Such QT prolongation has been linked to medication, including treatments for COVID-19, hydroxcholroquine and azithromycin, and is reversible on stopping the drug (77). Brady-arrhythmias have been described less frequently, although there are a number of reported cases of sinus node dysfunction, possibly caused by myocardial inflammation of the sino-atrial node (78).

\section{Paediatric multisystem inflammatory syndrome and kawasaki's disease}

Unlike other viral pandemics such as influenza, children and young adults appear far less likely to suffer severe COVID-19, representing only $1-2 \%$ of admitted patients (79). However, reports have emerged of a 'Paediatric multisystem inflammatory syndrome' in association with SARS-CoV2 infection. The European Centre for Disease Prevention and Control describes around 230 cases in the EU and UK with two deaths, although not all of these were confirmed to have COVID-19 (80). This condition appears to overlap with Kawasaki's disease, a vasculitis of unknown cause that can cause hypotension, cardiac dysfunction and coronary artery aneurysms, which may present with myocardial infarction or rupture (81). A recent report of a 30-fold increased incidence of Kawasaki's type response in the COVID-19 epicentre of Northern Italy $(82,83)$ raises the possibility that SARSCoV2 acts as a trigger for this disease, with the potential for an increase in the acute and late cardiac complications seen with this condition.

\section{Conclusions}

COVID-19 is associated with a high rate of detectible cardiac injury and a higher risk of thrombosis than similar critical illnesses. However, our fears of a large number of severe cardiac complications of COVID-19 have so far not materialised. It remains to be seen whether longerterm cardiac complications manifest as we follow up surviving patients and gain more experience with this new disease.

The numerous social restrictions and reallocation of healthcare resource towards combatting COVID19 are unfortunately likely to themselves cause a significant number of deaths and morbidity as routine and emergency healthcare is compromised. Reports from Italy suggest a reduction in the presentation of myocardial infarction during the epidemic by $26-30 \%$ with a corresponding increase in mortality $(84,85)$. A decrease in STEMI incidence during COVID-19 has also been noted in Northern Europe (86). We have seen this pattern repeated in our own service as patients are asked

This work is licensed under a Creative Commons Attribution-NonCommercial 4.0 International License. 
(overtly or subliminally) to triage and manage their own conditions without the necessary expertise and support. The cardiac effects of COVID-19 will not therefore be borne only by those who have contracted the disease and will be challenging to quantify for many years.

\section{Declaration of interest}

The authors declare that there is no conflict of interest that could be perceived as prejudicing the impartiality of this review.

\section{Funding}

This research did not receive any specific grant from any funding agency in the public, commercial or not-for-profit sector

\section{Author contribution statement}

The manuscript was conceived by T C and A A M and all authors contributed to its writing and content.

\section{References}

1 Inciardi RM, Lupi L, Zaccone G, Italia L, Raffo M, Tomasoni D Cani DS, Cerini M, Farina D, Gavazzi E, et al. Cardiac involvement in a patient with coronavirus disease 2019 (COVID-19). JAMA Cardiology 20205 819-824. (https://doi.org/10.1001/jamacardio.2020.1096)

2 Sala S, Peretto G, Gramegna M, Palmisano A, Villatore A, Vignale D, De Cobelli F, Tresoldi M, Cappelletti AM, Basso C, et al. Acute myocarditis presenting as a reverse Tako-Tsubo syndrome in a patient with SARS-CoV-2 respiratory infection. European Heart Journal 2020 41 1861-1862. (https://doi.org/10.1093/eurheartj/ehaa286)

3 Kumar K, Vogt JC, Divanji PH \& Cigarroa JE. Spontaneous coronary artery dissection of the left anterior descending artery in a patient with COVID-19 infection. Catheterization and Cardiovascular Interventions 2020 In press. (https://doi.org/10.1002/ccd.28960)

4 Kir D, Mohan C \& Sancassani R. Heart BRAKE-an unusual cardiac manifestation of coronavirus disease 2019 (COVID-19). JACC: Case Reports 20202 1252-1255. (https://doi.org/10.1016/j. jaccas.2020.04.026)

5 Coyle J, Igbinomwanhia E, Sanchez-Nadales A, Danciu S, Chu C \& Shah N. A recovered case of COVID-19 myocarditis and ARDS treated with corticosteroids, tocilizumab, and experimental AT-001. JACC: Case Reports 20202 1331-1336. (https://doi.org/10.1016/j. jaccas.2020.04.025)

6 Minhas AS, Scheel P, Garibaldi B, Liu G, Horton M, Jennings M, Jones SR, Michos ED \& Hays AG. Takotsubo syndrome in the setting of COVID-19 infection. JACC: Case Reports 20202 1321-1325.

7 Loghin C, Chauhan S \& Lawless SM. Pseudo acute myocardial infarction in a young COVID-19 patient. JACC: Case Reports 20202 1284-1288. (https://doi.org/10.1016/j.jaccas.2020.04.015)

8 Dabbagh MF, Aurora L, D'Souza P, Weinmann AJ, Bhargava P \& Basir MB. Cardiac tamponade secondary to COVID-19. JACC: Case Reports 20202 1326-1330. (https://doi.org/10.1016/j. jaccas.2020.04.009)

9 Ullah W, Saeed R, Sarwar U, Patel R \& Fischman DL. COVID19 complicated by acute pulmonary embolism and right-sided heart failure. JACC: Case Reports 20202 1379-1382. (https://doi org/10.1016/j.jaccas.2020.04.008)

10 Bemtgen X, Kruger K, Supady A, Durschmied D, Schibilsky D, Bamberg F, Bode C, Wengenmayer T \& Staudacher DL. First successful treatment of COVID-19 induced refractory cardiogenic plus vasoplegic shock by combination of pVAD and ECMO - a case report. ASAIO Journal 202066 607-609. (https://doi.org/10.1097/ MAT.0000000000001178)

11 Zeng JH, Liu YX, Yuan J, Wang FX, Wu WB, Li JX, Wang LF, Gao H, Wang Y, Dong CF, et al. First case of COVID-19 complicated with fulminant myocarditis: a case report and insights. Infection 202048 773-777. (https://doi.org/10.1007/s15010-020-01424-5)

12 Seecheran R, Narayansingh R, Giddings S, Rampaul M, Furlonge K, Abdool K, Bhagwandass N \& Seecheran NA. Atrial arrhythmias in a patient presenting with coronavirus disease-2019 (COVID-19) infection. Journal of Investigative Medicine High Impact Case Reports 202082324709620925571 . (https://doi. org/10.1177/2324709620925571)

13 Hua A, O'Gallagher K, Sado D \& Byrne J. Life-threatening cardiac tamponade complicating myo-pericarditis in COVID-19. European Heart Journal 202041 2130. (https://doi.org/10.1093/eurheartj/ ehaa253)

14 Kochi AN, Tagliari AP, Forleo GB, Fassini GM \& Tondo C. Cardiac and arrhythmic complications in patients with COVID-19. Journal of Cardiovascular Electrophysiology 202031 1003-1008. (https://doi. org/10.1111/jce.14479)

15 Guzik TJ, Mohiddin SA, Dimarco A, Patel V, Savvatis K, MarelliBerg FM, Madhur MS, Tomaszewski M, Maffia P, D'Acquisto F, et al. COVID-19 and the cardiovascular system: implications for risk assessment, diagnosis, and treatment options. Cardiovascular Research 2020116 1666-1687. (https://doi.org/10.1093/cvr/ cvaa106)

16 Long B, Brady WJ, Koyfman A \& Gottlieb M. Cardiovascular complications in COVID-19. American Journal of Emergency Medicine 202038 1504-1507. (https://doi.org/10.1016/j.ajem.2020.04.048)

17 Atri D, Siddiqi HK, Lang JP, Nauffal V, Morrow DA \& Bohula EA. COVID-19 for the cardiologist. JACC: Basic to Translational Science 20205 518-536. (https://doi.org/10.1016/j.jacbts.2020.04.002)

18 Madjid M, Safavi-Naeini P, Solomon SD \& Vardeny O. Potential effects of coronaviruses on the cardiovascular system: a review. JAMA Cardiology 20205 831-840. (https://doi.org/10.1001/ jamacardio.2020.1286)

19 Kendall EJ, Bynoe ML \& Tyrrell DA. Virus isolations from common colds occurring in a residential school. BMJ 19622 82-86. (https:// doi.org/10.1136/bmj.2.5297.82)

20 Tyrrell DA \& Bynoe ML. Cultivation of a novel type of commoncold virus in organ cultures. BMJ 19651 1467-1470. (https://doi. org/10.1136/bmj.1.5448.1467)

21 Su S, Wong G, Shi W, Liu J, Lai ACK, Zhou J, Liu W, Bi Y \& Gao GF. Epidemiology, genetic recombination, and pathogenesis of coronaviruses. Trends in Microbiology 201624 490-502. (https://doi. org/10.1016/j.tim.2016.03.003)

22 Troughton RW, Asher CR \& Klein AL. Pericarditis. Lancet 2004363 717-727. (https://doi.org/10.1016/S0140-6736(04)15648-1)

23 Sagar S, Liu PP \& Cooper Jr LT. Myocarditis. Lancet 2012379 738-747. (https://doi.org/10.1016/S0140-6736(11)60648-X)

24 Kearney MT, Cotton JM, Richardson PJ \& Shah AM. Viral myocarditis and dilated cardiomyopathy: mechanisms, manifestations, and management. Postgraduate Medical Journal 200177 4-10. (https://doi. org/10.1136/pmj.77.903.4)

25 Kuhl U, Pauschinger M, Noutsias M, Seeberg B, Bock T, Lassner D, Poller W, Kandolf R \& Schultheiss HP. High prevalence of viral genomes and multiple viral infections in the myocardium of adults with 'idiopathic' left ventricular dysfunction. Circulation 2005111 887-893. (https://doi.org/10.1161/01.CIR.0000155616.07901.35) 
26 Song Z, Xu Y, Bao L, Zhang L, Yu P, Qu Y, Zhu H, Zhao W, Han Y $\&$ Qin C. From SARS to MERS, thrusting coronaviruses into the spotlight. Viruses 201911 59. (https://doi.org/10.3390/v11010059)

27 Wang JT \& Chang SC. Severe acute respiratory syndrome. Current Opinion in Infectious Diseases 200417 143-148. (https://doi. org/10.1097/00001432-200404000-00013)

28 Peiris JS, Guan Y \& Yuen KY. Severe acute respiratory syndrome. Nature Medicine 200410 (Supplement) S88-S97. (https://doi. org/10.1038/nm1143)

29 Li W, Moore MJ, Vasilieva N, Sui J, Wong SK, Berne MA, Somasundaran M, Sullivan JL, Luzuriaga K, Greenough TC, et al. Angiotensin-converting enzyme 2 is a functional receptor for the SARS coronavirus. Nature 2003426 450-454. (https://doi. org/10.1038/nature02145)

30 Yan R, Zhang Y, Li Y, Xia L, Guo Y \& Zhou Q. Structural basis for the recognition of SARS-CoV-2 by full-length human ACE2. Science 2020 367 1444-1448. (https://doi.org/10.1126/science.abb2762)

31 Ding Y, Wang H, Shen H, Li Z, Geng J, Han H, Cai J, Li X, Kang W, Weng D, et al. The clinical pathology of severe acute respiratory syndrome (SARS): a report from China. Journal of Pathology 2003200 282-289. (https://doi.org/10.1002/path.1440)

32 Yu CM, Wong RS, Wu EB, Kong SL, Wong J, Yip GW, Soo YO, Chiu ML, Chan YS, Hui D, et al. Cardiovascular complications of severe acute respiratory syndrome. Postgraduate Medical Journal 2006 82 140-144. (https://doi.org/10.1136/pgmj.2005.037515)

33 Lau ST, Yu WC, Mok NS, Tsui PT, Tong WL \& Cheng SW. Tachycardia amongst subjects recovering from severe acute respiratory syndrome (SARS). International Journal of Cardiology 2005100 167-169. (https:// doi.org/10.1016/j.ijcard.2004.06.022)

34 Pan SF, Zhang HY, Li CS \& Wang C. Cardiac arrest in severe acute respiratory syndrome: analysis of 15 cases. Chinese Journal of Tuberculosis and Respiratory Diseases 200326 602-605.

35 Chan JW, Ng CK, Chan YH, Mok TY, Lee S, Chu SY, Law WL, Lee MP $\&$ Li PC. Short term outcome and risk factors for adverse clinical outcomes in adults with severe acute respiratory syndrome (SARS). Thorax 200358 686-689. (https://doi.org/10.1136/thorax.58.8.686)

36 Yang JK, Feng Y, Yuan MY, Yuan SY, Fu HJ, Wu BY, Sun GZ, Yang GR, Zhang XL, Wang L, et al. Plasma glucose levels and diabetes are independent predictors for mortality and morbidity in patients with SARS. Diabetic Medicine 200623 623-628. (https://doi.org/10.1111/ j.1464-5491.2006.01861.x)

37 Chan-Yeung M \& Xu RH. SARS: epidemiology. Respirology 20038 (Supplement) S9-S14. (https://doi.org/10.1046/j.14401843.2003.00518.x)

38 Zhong NS, Zheng BJ, Li YM, Poon XZH, Xie ZH, Chan KH, Li PH, Tan SY, Chang Q, Xie JP, et al. Epidemiology and cause of severe acute respiratory syndrome (SARS) in Guangdong, People's Republic of China, in February, 2003. Lancet 2003362 1353-1358. (https:// doi.org/10.1016/s0140-6736(03)14630-2)

39 Alhogbani T. Acute myocarditis associated with novel Middle East respiratory syndrome coronavirus. Annals of Saudi Medicine 201636 78-80. (https://doi.org/10.5144/0256-4947.2016.78)

40 Assiri A, Al-Tawfiq JA, Al-Rabeeah AA, Al-Rabiah FA, Al-Hajjar S, Al-Barrak A, Flemban H, Al-Nassir WN, Balkhy HH, Al-Hakeem RF, et al. Epidemiological, demographic, and clinical characteristics of 47 cases of Middle East respiratory syndrome coronavirus disease from Saudi Arabia: a descriptive study. Lancet: Infectious Diseases 201313 752-761. (https://doi.org/10.1016/S1473-3099(13)70204-4)

41 Al-Abdallat MM, Payne DC, Alqasrawi S, Rha B, Tohme RA, Abedi GR, Al Nsour M, Iblan I, Jarour N, Farag NH, et al. Hospitalassociated outbreak of Middle East respiratory syndrome coronavirus: a serologic, epidemiologic, and clinical description. Clinical Infectious Diseases 201459 1225-1233. (https://doi.org/10.1093/cid/ciu359)

42 Badawi A \& Ryoo SG. Prevalence of comorbidities in the Middle East respiratory syndrome coronavirus (MERS-CoV): a systematic review and meta-analysis. International Journal of Infectious Diseases 201649 129-133. (https://doi.org/10.1016/j.ijid.2016.06.015)

43 Mehra MR, Desai SS, Kuy S, Henry TD \& Patel AN. Cardiovascular disease, drug therapy, and mortality in Covid-19. New England Journal of Medicine 2020382 e102. (https://doi.org/10.1056/NEJMoa2007621)

44 Docherty AB, Harrison EM, Green CA, Hardwick HE, Pius R, Norman L, Holden KA, Read JM, Dondelinger F, Carson G, et al. Features of 20133 UK patients in hospital with covid-19 using the ISARIC WHO Clinical Characterisation Protocol: prospective observational cohort study. BMJ 2020369 m1985. (https://doi. org/10.1136/bmj.m1985)

45 Huang C, Wang Y, Li X, Ren L, Zhao J, Hu Y, Zhang L, Fan G, Xu J, $\mathrm{Gu}$ X, et al. Clinical features of patients infected with 2019 novel coronavirus in Wuhan, China. Lancet 2020395 497-506. (https:// doi.org/10.1016/S0140-6736(20)30183-5)

46 Wang D, Hu B, Hu C, Zhu F, Liu X, Zhang J, Wang B, Xiang H, Cheng Z, Xiong Y, et al. Clinical characteristics of 138 hospitalized patients with 2019 novel coronavirus-infected pneumonia in Wuhan, China. JAMA 2020323 1061-1069. (https://doi. org/10.1001/jama.2020.1585)

47 Guo T, Fan Y, Chen M, Wu X, Zhang L, He T, Wang H, Wan J, Wang X \& Lu Z. Cardiovascular implications of fatal outcomes of patients with coronavirus disease 2019 (COVID-19). JAMA Cardiology 20205 811-818. (https://doi.org/10.1001/jamacardio.2020.1017)

48 Shi S, Qin M, Shen B, Cai Y, Liu T, Yang F, Gong W, Liu X, Liang J, Zhao Q, et al. Association of cardiac injury with mortality in hospitalized patients with COVID-19 in Wuhan, China. JAMA Cardiology 20205 802-810. (https://doi.org/10.1001/ jamacardio.2020.0950)

49 Tersalvi G, Vicenzi M, Calabretta D, Biasco L, Pedrazzini G \& Winterton D. Elevated troponin in patients with coronavirus disease 2019: possible mechanisms. Journal of Cardiac Failure 202026 470-475. (https://doi.org/10.1016/j.cardfail.2020.04.009)

50 Caforio ALP, Pankuweit S, Arbustini E, Basso C, Gimeno-Blanes J, Felix SB, Fu M, Helio T, Heymans S, Jahns R, et al. Current state of knowledge on aetiology, diagnosis, management, and therapy of myocarditis: a position statement of the European Society of Cardiology Working Group on myocardial and pericardial diseases. European Heart Journal 201334 2636-2648. (https://doi.org/10.1093/ eurheartj/eht210)

$51 \mathrm{Hu} \mathrm{H}$, Ma F, Wei X \& Fang Y. Coronavirus fulminant myocarditis saved with glucocorticoid and human immunoglobulin. European Heart Journal 2020 ehaa190. (https://doi.org/10.1093/eurheartj/ ehaa190)

52 Frencken JF, van Baal L, Kappen TH, Donker DW, Horn J, van der Poll T, van Klei WA, Bonten MJM, Cremer OL \& Members of the MARS Consortium. Myocardial injury in critically ill patients with community-acquired pneumonia. A cohort study. Annals of the American Thoracic Society 201916 606-612. (https://doi.org/10.1513/ AnnalsATS.201804-286OC)

53 Chang CL, Mills GD, Karalus NC, Jennings LC, Laing R, Murdoch DR, Chambers ST, Vettise D, Tuffery CM \& Hancox RJ. Biomarkers of cardiac dysfunction and mortality from communityacquired pneumonia in adults. PLoS ONE 20138 e62612. (https:// doi.org/10.1371/journal.pone.0062612)

54 d'Alessandro E, Becker C, Bergmeier W, Bode C, Bourne JH, Brown H, Buller HR, Ten Cate-Hoek AJ, Ten Cate V, van Cauteren YJM, et al. Thrombo-inflammation in cardiovascular disease: an expert consensus document from the third Maastricht consensus conference on thrombosis. Thrombosis and Haemostasis 2020120 538-564. (https://doi.org/10.1055/s-0040-1708035)

55 Tang N, Li D, Wang X \& Sun Z. Abnormal coagulation parameters are associated with poor prognosis in patients with novel coronavirus pneumonia. Journal of Thrombosis and Haemostasis 202018 844-847. (https://doi.org/10.1111/jth.14768) 
56 Zhang L, Yan X, Fan Q, Liu H, Liu X, Liu Z \& Zhang Z. D-dimer levels on admission to predict in-hospital mortality in patients with covid-19. Journal of Thrombosis and Haemostasis 202018 1324-1329. (https://doi.org/10.1111/jth.14859)

57 Tang N, Bai H, Chen X, Gong J, Li D \& Sun Z. Anticoagulant treatment is associated with decreased mortality in severe coronavirus disease 2019 patients with coagulopathy. Journal of Thrombosis and Haemostasis 202018 1094-1099. (https://doi. org/10.1111/jth.14817)

58 Lillicrap D. Disseminated intravascular coagulation in patients with 2019-nCoV pneumonia. Journal of Thrombosis and Haemostasis 2020 18 786-787. (https://doi.org/10.1111/jth.14781)

59 Thomas MR, Outteridge SN, Ajjan RA, Phoenix F, Sangha GK, Faulkner RE, Ecob R, Judge HM, Khan H, West LE, et al. Platelet P2Y12 inhibitors reduce systemic inflammation and its prothrombotic effects in an experimental human model. Arteriosclerosis, Thrombosis, and Vascular Biology 201535 2562-2570. (https://doi.org/10.1161/ATVBAHA.115.306528)

60 Poissy J, Goutay J, Caplan M, Parmentier E, Duburcq T, Lassalle F, Jeanpierre E, Rauch A, Labreuche J, Susen S, et al. Pulmonary embolism in COVID-19 patients: awareness of an increased prevalence. Circulation 2020142 184-186. (https://doi.org/10.1161/ CIRCULATIONAHA.120.047430)

61 Klok FA, Kruip MJHA, van der Meer NJM, Arbous MS, Gommers DAMPJ, Kant KM, Kaptein FHJ, van Paassen J, Stals MAM, Huisman MV, et al. Incidence of thrombotic complications in critically ill ICU patients with COVID-19. Thrombosis Research 2020 191 145-147. (https://doi.org/10.1016/j.thromres.2020.04.013)

62 Klok FA, Kruip MJHA, van der Meer NJM, Arbous MS, Gommers D, Kant KM, Kaptein FHJ, van Paassen J, Stals MAM, Huisman MV, et al. Confirmation of the high cumulative incidence of thrombotic complications in critically ill ICU patients with COVID-19: an updated analysis. Thrombosis Research 2020191 148-150. (https:// doi.org/10.1016/j.thromres.2020.04.041)

63 Varga Z, Flammer AJ, Steiger P, Haberecker M, Andermatt R, Zinkernagel AS, Mehra MR, Schuepbach RA, Ruschitzka F \& Moch H. Endothelial cell infection and endotheliitis in COVID19. Lancet 2020395 1417-1418. (https://doi.org/10.1016/S01406736(20)30937-5)

64 Schulman S. Coronavirus disease 2019, prothrombotic factors, and venous thromboembolism. Seminars in Thrombosis and Hemostasis 202046 772-776. (https://doi.org/10.1055/s-0040-1710337)

65 McGonagle D, O’Donnell JS, Sharif K, Emery P \& Bridgewood C. Immune mechanisms of pulmonary intravascular coagulopathy in COVID-19 pneumonia. Lancet Rheumatology 20202 e437-e445. (https://doi.org/10.1016/S2665-9913(20)30121-1)

66 Beyrouti R, Adams ME, Benjamin L, Cohen H, Farmer SF, Goh YY, Humphries F, Jäger HR, Losseff NA, Perry RJ, et al. Characteristics of ischaemic stroke associated with COVID-19. Journal of Neurology, Neurosurgery, and Psychiatry 202091 889-891. (https://doi. org/10.1136/jnnp-2020-323586)

67 Valderrama EV, Humbert K, Lord A, Frontera J \& Yaghi S. Severe acute respiratory syndrome coronavirus 2 infection and ischemic stroke. Stroke 202051 e124-e127. (https://doi.org/10.1161/ STROKEAHA.120.030153)

68 Cattaneo M, Bertinato EM, Birocchi S, Brizio C, Malavolta D Manzoni M, Muscarella G \& Orlandi M. Pulmonary embolism or pulmonary thrombosis in COVID-19? Is the recommendation to use high-dose heparin for thromboprophylaxis justified? Thrombosis and Haemostasis 2020120 1230-1232. (https://doi. org/10.1055/s-0040-1712097)

69 Thachil J \& Srivastava A. SARS-2 coronavirus-associated hemostatic lung abnormality in COVID-19: is it pulmonary thrombosis or pulmonary embolism? Seminars in Thrombosis and Hemostasis 2020 46 777-780. (https://doi.org/10.1055/s-0040-1712155)
70 Paranjpe I, Fuster V, Lala A, Russak AJ, Glicksberg BS, Levin MA, Charney AW, Narula J, Fayad ZA, Bagiella E, et al. Association of treatment dose anticoagulation with in-hospital survival among hospitalized patients with COVID-19. Journal of the American College of Cardiology 202076 122-124. (https://doi.org/10.1016/j. jacc.2020.05.001)

71 Helms J, Tacquard C, Severac F, Leonard-Lorant I, Ohana M, Delabranche X, Merdji H, Clere-Jehl R, Schenck M, Fagot Gandet F, et al. High risk of thrombosis in patients with severe SARS-CoV-2 infection: a multicenter prospective cohort study. Intensive Care Medicine 202046 1089-1098. (https://doi.org/10.1007/s00134-02006062-x)

72 Perini P, Nabulsi B, Massoni CB, Azzarone M \& Freyrie A. Acute limb ischaemia in two young, non-atherosclerotic patients with COVID-19. Lancet 2020395 1546. (https://doi.org/10.1016/S01406736(20)31051-5)

73 Liu K, Fang YY, Deng Y, Liu W, Wang MF, Ma JP, Xiao W, Wang YN, Zhong $\mathrm{MH}$, Li CH, et al. Clinical characteristics of novel coronavirus cases in tertiary hospitals in Hubei Province. Chinese Medical Journal 2020133 1025-1031. (https://doi.org/10.1097/ CM9.0000000000000744)

74 Bhatla A, Mayer MM, Adusumalli S, Hyman MC, Oh E, Tierney A, Moss J, Chahal AA, Anesi G, Denduluri S, et al. COVID-19 and cardiac arrhythmias. Heart Rhythm 202017 1439-1444. (https://doi. org/10.1016/j.hrthm.2020.06.016)

75 Colafrancesco S, Alessandri C, Conti F \& Priori R. COVID-19 gone bad: a new character in the spectrum of the hyperferritinemic syndrome? Autoimmunity Reviews 202019 102573. (https://doi. org/10.1016/j.autrev.2020.102573)

76 Shao F, Xu S, Ma X, Xu Z, Lyu J, Ng M, Cui H, Yu C, Zhang Q, Sun $\mathrm{P}$, et al. In-hospital cardiac arrest outcomes among patients with COVID-19 pneumonia in Wuhan, China. Resuscitation 2020151 18-23. (https://doi.org/10.1016/j.resuscitation.2020.04.005)

77 Chorin E, Dai M, Shulman E, Wadhwani L, Bar-Cohen R, Barbhaiya C, Aizer A, Holmes D, Bernstein S, Spinelli M, et al. The QT interval in patients with COVID-19 treated with hydroxychloroquine and azithromycin. Nature Medicine 202026 808-809. (https://doi. org/10.1038/s41591-020-0888-2)

78 Amaratunga EA, Corwin DS, Moran L \& Snyder R. Bradycardia in patients with COVID-19: a calm before the storm? Cureus 202012 e8599. (https://doi.org/10.7759/cureus.8599)

79 Docherty AB, Harrison EM, Green CA, Hardwick HE, Pius R, Norman L, Holden KA, Read JM, Dondelinger F, Carson G et al. Features of 20,133 UK patients in hospital with covid-19 using the ISARIC WHO Clinical Characterisation Protocol: prospective observational cohort study. BMJ 2020369 m1985. (https://doi. org/10.1136/ bmj.m1985)

80 ECDPC. Rapid risk assessment: paediatric inflammatory multisystem syndrome and SARS-CoV-2 infection in children, 2020. (available at: https://www.ecdc.europa.eu/en/publications-data/paediatricinflammatory-multisystem-syndrome-and-sars-cov-2-rapid-riskassessment)

81 Shulman ST \& Rowley AH. Kawasaki disease: insights into pathogenesis and approaches to treatment. Nature Reviews: Rheumatology 201511 475-482. (https://doi.org/10.1038/ nrrheum.2015.54)

82 Viner RM \& Whittaker E. Kawasaki-like disease: emerging complication during the COVID-19 pandemic. Lancet 2020395 1741-1743. (https://doi.org/10.1016/S01406736(20)31129-6)

83 Verdoni L, Mazza A, Gervasoni A, Martelli L, Ruggeri M, Ciuffreda M, Bonanomi E \& D'Antiga L. An outbreak of severe Kawasaki-like disease at the Italian epicentre of the SARS-CoV-2 epidemic: an observational cohort study. Lancet 2020395 1771-1778. (https://doi. org/10.1016/S0140-6736(20)31103-X)
(C) 2020 The authors Published by Bioscientifica Ltd
This work is licensed under a Creative Commons Attribution-NonCommercial 4.0 International License. ded from Bioscientifica com at $04 / 26 / 2023 \quad 12: 45: 36 \mathrm{PM}$ 
84 De Filippo O, D’Ascenzo F, Angelini F, Bocchino PP, Conrotto F, Saglietto A, Secco GG, Campo G, Gallone G, Verardi R, et al. Reduced rate of hospital admissions for ACS during covid-19 outbreak in Northern Italy. New England Journal of Medicine 2020383 88-89. (https://doi.org/10.1056/NEJMc2009166)

85 De Rosa S, Spaccarotella C, Basso C, Calabro MP, Curcio A, Filardi PP, Mancone M, Mercuro G, Muscoli S, Nodari S, et al. Reduction of hospitalizations for myocardial infarction in Italy in the
COVID-19 era. European Heart Journal 202041 2083-2088. (https:// doi.org/10.1093/eurheartj/ehaa409)

86 Piuhola J, Kerkela R, Laine M, Andersen GØ, Erglis A, Kumsars I, Thuesen L, Sinisalo J, Niemelä M \& Junttila MJ. Lower ST-elevation myocardial infarction incidence during COVID-19 epidemic in northern Europe. Scandinavian Cardiovascular Journal 2020 In pr. (https://doi.org/10.1080/14017431 2020.1820563)

Received in final form 13 October 2020

Accepted 20 October 2020

Accepted Manuscript published online 20 October 2020 (c) 2020 The authors Published by Bioscientifica Ltd 